Jurnal IImu Keperawatan Medikal Bedah 3 (1), Mei 2020, 1-76

ISSN 2338-2058 (print), ISSN 2621-2986 (online)

\title{
Hubungan antara Interdialytic Weight Gain dengan Perubahan Tekanan Darah Intradialisis pada Pasien Chronic Kidney Diseases
}

\author{
Ni Kadek Yuni Lestari ${ }^{1}$, Ni Luh Gede Intan Saraswati ${ }^{2}$ \\ ${ }^{1,2}$ Sekolah Tinggi Ilmu Kesehatan Wira Medika Bali, Indonesia \\ Corresponding Author: yunilestariwika@gmail.com
}

\begin{abstract}
Abstrak
Pasien CKD (Chronic Kidney Diseases) yang menjalani hemodialisis sering mengalami komplikasi gangguan hemodinamik baik itu hipertensi maupun hipotensi intradialisis. Salah satu penyebab yang paling sering adalah peningkatan IDWG (Interdialytic Weight Gain). Tujuan penelitian ini adalah untuk menganalisis hubungan antara IDWG (Interdialytic Weight Gain) dengan perubahan tekanan darah intradialisis pada pasien CKD di Ruang Hemodialisis RSUP Sanglah Denpasar. Metode penelitian yang digunakan adalah analitik korelasi dengan pendekatan cross sectional. Teknik sampel yang digunakan adalah purposive sampling dengan jumlah sampel sebanyak 80 responden. Analisis statistik dengan menggunakan spearmans rank. Hasil penelitian didapatkan dari 80 responden sebagian besar mempunyai interdialytic weight gain dalam kategori ringan $(73,8,0 \%)$ dan tekanan darah intradialisis dalam batas normal $(65,0 \%)$. Hasil uji statistik menunjukkan $p$ value $0,001(<0,05)$. Kesimpulan dari penelitian ini bahwa ada hubungan yang signifikan antara interdialytic weight gain dengan perubahan tekanan darah intradialisis pada pasien chronic kidney diseases di Ruang Hemodialisis RSUP Sanglah Denpasar. Berdasarkan hasil penelitian ini bahwa perawat diharapkan dapat meningkatkan pemberian edukasi secara berkala pada pasien hemodialisis reguler untuk meningkatkan kepatuhan pasien pada diet dan pembatasan intake cairan.
\end{abstract}

Kata kunci: hemodialisis, interdialytic weight gain, tekanan darah

\begin{abstract}
Chronic Kidney Diseases (CKD) patients who undergo hemodialysis often experience complications of haemodynamic disorders, both hypertension and intradialisis hypotension. One of the most frequent causes of increasing is IDGW (Interdialytic Weight Gain). The purpose of this study was to determine the correlation between interdialytic weight gain and changes in intradialysis blood pressure among patients with chronic kidney diseases in Haemodialysis Room at Sanglah Hospital Denpasar. The research method used is analytic correlation with cross sectional approach. The sample technique used was purposive sampling with a total sample of 80 respondents. Statistical analysis using spearmans rank statistic test. The results obtained from 80 respondents most mostly interdialytic weight gain in the mild category (73.8.0\%) and intradialisis blood pressure within normal limits (65.0\%). The result of statistic test shows that p value 0,001 $(<0,05)$. The conclusion of this study is that any significant correlation between interdialytic weight gain with changes in intradialysis blood pressure among patients with CKD at Haemodialysis Room of Sanglah Hospital Denpasar. Suggestions for nurses to increase the provision of regular education in regular haemodialysis patients to improve patient's adherence to diet and limit fluid intake.
\end{abstract}

Keywords: haemodialysis, interdialytic weight gain, blood pressure

Lestari \& Saraswati / Hubungan antara interdialytic weight gain dengan perubahan tekanan darah... 32 
Jurnal IImu Keperawatan Medikal Bedah 3 (1), Mei 2020, 1-76

ISSN 2338-2058 (print), ISSN 2621-2986 (online)

\section{PENDAHULUAN}

Chronic Kidney Diseases (CKD) merupakan kerusakan fungsi ginjal di mana ginjal tidak dapat membuang racun dan produk sisa dari darah. CKD ditandai dengan adanya protein dalam urin serta penurunan laju filtrasi glomerulus yang berlangsung lebih dari 3 bulan (Black \& Hawks, 2009). Terapi pengganti ginjal dapat berupa hemodialisis, dialisis peritoneal, dan transplantasi ginjal. Hemodialisis merupakan terapi pengganti ginjal yang paling banyak dipilih di dunia termasuk Indonesia sehingga permintaan hemodialisis semakin meningkat dari tahun ke tahun (Baradero, Dayrit, \& Siswadi, 2009).

United State Renal Data System (USRDS) di Amerika Serikat menunjukkan prevalensi CKD meningkat sebesar 20-25\% setiap tahunnya dengan data terakhir tahun 2014 terdapat 116.395 orang penderita CKD yang baru (USRDS, 2009). Data Kementrian Kesehatan Indonesia prevalensi penyakit ginjal kronik sebesar $2 \%$ dari total penduduk atau sekitar 499.800 orang (Kemenkes RI, 2018).

Data Indonesian Renal Registry (IRR) dari 433 renal unit yang melapor, tercatat 30.831 pasien aktif menjalani dialisis pada tahun 2017, sebagian besar adalah pasien dengan penyakit ginjal kronik (Infodatin, 2017). Prevalensi CKD di Provinsi Bali tahun 2017, tercatat sebanyak 38.284 orang. Dari jumlah tersebut sebagian besar menjalani pengobatan yaitu hemodialisis di Rumah Sakit Sanglah Denpasar yaitu sebanyak 4703 orang (Laporan Tahunan Instalasi Pelayanan Dialisis RSUP Sanglah Denpasar, 2017).

Hemodialisis merupakan suatu proses yang digunakan untuk mengeluarkan cairan dan produk limbah dari dalam tubuh ketika ginjal tidak mampu melaksanakan fungsi tersebut. Hemodialisis dapat memperpanjang usia tanpa batas yang jelas, namun pasien HD tetap akan mengalami sejumlah permasalahan dan komplikasi (Smeltzer \& Bare, 2008). Komplikasi yang terjadi pada pasien hemodialisis diantaranya adalah hipotensi, hipertensi, kram otot, mual, muntah, sakit kepala, sakit dada, sakit punggung, gatal, demam, dan menggigil. Komplikasi yang cukup sering terjadi adalah gangguan hemodinamik (tekanan darah), baik hipotensi maupun hipertensi intradialisis (Rahardjo et al., 2009).

Tekanan darah umumnya menurun dengan dilakukannya Ultrafiltrasi (UF) atau penarikan cairan saat hemodialisis dengan frekuensi terjadinya penurunan tekanan darah (hipotensi) sebesar 20-30\% dari pasien yang menjalani HD reguler. Komplikasi lainnya yang dapat terjadi selama 
Jurnal IImu Keperawatan Medikal Bedah 3 (1), Mei 2020, 1-76

ISSN 2338-2058 (print), ISSN 2621-2986 (online)

pasien menjalani hemodialisis adalah peningkatan tekanan darah dan dilaporkan sekitar 5-15\% dari pasien yang menjalani hemodialisis regular tekanan darahnya justru meningkat saat hemodialisis. Kondisi ini disebut Hipertensi Intradialitik (HID) atau interdialytic hypertension (Armiyati, 2015). Komplikasi hipertensi intradialitik di RSUP Sanglah tercatat ada 3219 orang dan angka kejadiannya hipotensi sebanyak 160 orang pada tahun 2017 dari total seluruh pasien HD (Laporan Tahunan Instalasi Pelayanan Dialisis, 2017).

Perubahan tekanan darah intradialisis adalah suatu kondisi berupa terjadinya peningkatan atau penurunan tekanan darah pada saat hemodialisis atau tekanan darah selama dan pada saat akhir dari hemodialisis lebih tinggi atau lebih rendah dari tekanan darah saat memulai hemodialisis (Chazot \& Jean, 2010). Komplikasi hipotensi dan hipertensi intradialisis dapat terjadi selama hemodialisis dan bisa berpengaruh pada komplikasi lain seperti terjadinya gagal jantung, pada organ paru komplikasi yang paling sering terjadi adalah edema paru, sedangkan pada otak dapat menyebabkan ensefalopati hipertensif. Komplikasi ini dapat mengakibatkan timbulnya masalah baru yang lebih kompleks antara lain ketidaknyamanan, meningkatkan stress, dan mempengaruhi kualitas hidup memperburuk kondisi pasien bahkan menimbulkan kematian (Armiyanti, 2015).

Patofisiologi terjadinya perubahan tekanan darah intradialisis disebabkan oleh beberapa faktor yaitu faktor usia, interdialytic weight gain, ureum reduction ratio, residual renal function, lama hemodialisis, jumlah obat antihipertensi, kadar hemoglobin, dan kecepatan aliran darah selama hemodialisis. Peningkatan volume cairan diantara dua waktu dialisis yang dimanifestasi dengan penambahan berat badan interdialytic merupakan faktor penyebab terbanyak terjadinya perubahan tekanan darah (Chazot \& Jean, 2010).

Penanganan masalah perubahan tekanan darah pada pasien intradialisis di RSUP Sanglah sebenarnya sudah ada protapnya terutama masalah hipotensi. Petugas kesehatan yang bertugas di ruang hemodialisis sudah melakukan penyuluhan kesehatan mengenai penyebab dan komplikasi yang bisa muncul apabila terjadi perubahan tekanan darah yang terlalu jauh, akan tetapi permasalah hipotensi dan hipertensi intradialisis masih selalu terjadi.

Interdialytic Weight Gain (IDWG) adalah selisih berat badan pradialisis dengan berat badan pascadialisis sesi sebelumnya (Suwitra, 2009). Kamyar (2009) dari Pusat Penelitian Penyakit Ginjal di California menemukan bahwa $86 \%$ dari pasien yang menjalani Hemodialisis memiliki berat badan interdialytic lebih dari 1,5 kg. Kenaikan berat badan 1 kilogram sama dengan 
Jurnal IImu Keperawatan Medikal Bedah 3 (1), Mei 2020, 1-76

ISSN 2338-2058 (print), ISSN 2621-2986 (online)

satu liter air yang dikonsumsi pasien. Kenaikan berat badan antar sesi hemodialisis yang ditoleransi oleh tubuh yaitu antara 2,5\% sampai 3,5\% dari berat badan kering untuk mencegah resiko terjadinya masalah kardiovaskuler. IDWG dapat dikategorikan ringan kenaikan berat badan $<4 \%$, sedang dengan kenaikan 4-6\% dan berat dengan kenaikan berat badan $8 \%$ akan meningkatkan mortalitas pada pasien CKD (Kozier, 2010).

Interdialytic weight gain merupakan salah satu faktor yang dapat dikontrol untuk mencegah terjadinya hipertensi intradialisis. Selain itu, menurut Peixoto (2011) dengan membatasi peningkatan berat badan antar sesi dialisis dan menurunkan secara bertahap berat badan kering merupakan penanganan pertama terhadap hipertensi intradialisis. Hal ini bisa dicapai melalui konseling diet, pembatasan konsumsi garam, dan ultrafiltrasi yang agresif saat hemodialisis. Hal itu diperkuat oleh penelitian Locatelli, Cavalli, \& Tucci (2010) bahwa pengontrolan terhadap volume overload adalah tindakan yang paling penting dalam mencegah dan menangani pasien dengan hipertensi intradialisis.

Hasil studi pendahuluan yang dilakukan di Ruang Hemodialisis RSUP Sanglah Denpasar, didapatkan jumlah pasien yang mengalami HD rutin 2x/minggu di Instalasi Pelayanan Dialisis tiga bulan terakhir yaitu bulan Juni, Juli, Agustus pada tahun 2018 rata-rata sebanyak 264 orang. IDWG rata-rata pasien di Ruang Hemodialisis berkisar 3-4,5\%. Hasil observasi menunjukkan pasien HD ada yang mengalami peningkatan tekanan darah yang ditandai dengan hasil pengukuran tekanan darah pradialisis didapatkan rata-rata tekanan sistolik $>140 \mathrm{mmHg}$ dan rata-rata tekanan diastolik $>90 \mathrm{mmHg}$. Perubahan tekanan darah terjadi pada saat intradialisis yaitu rata-rata tekanan darah sistolik meningkat menjadi $>160 \mathrm{mmHg}$ dan tekanan diastolik rata-rata $>100 \mathrm{mmHg}$ yang ditandai dengan keluhan pasien sakit kepala. Pasien HD juga ada yang mengalami penurunan tekanan darah yang ditandai dengan hasil pengukuran tekanan darah didapatkan rata-rata tekanan sistolik $<100$ $\mathrm{mmHg}$ dan rata-rata tekanan diastolik $<60 \mathrm{mmHg}$ yang ditandai dengan keluhan pasien seperti kepala pusing, pengeliatan kabur, keluar keringat dingin, kram otot, serta telinga berdenging. Berdasarkan masalah tersebut, maka penting untuk dilakukan penelitian tentang hubungan interdialytic weight gain dengan perubahan tekanan darah intradialisis pada pasien chronic kidney diseases di Ruang Hemodialisis RSUP Sanglah Denpasar. 
Jurnal IImu Keperawatan Medikal Bedah 3 (1), Mei 2020, 1-76

ISSN 2338-2058 (print), ISSN 2621-2986 (online)

\section{METODE PENELITIAN}

Jenis penelitian ini adalah penelitian analitik korelasi dengan pendekatan cross sectional. Penelitian dilaksanakan di Ruang Hemodialisis RSUP Sanglah Denpasar mulai tanggal 10 sampai dengan 24 Desember 2018. Sampel penelitian ini memenuhi kriteria inklusi berupa pasien dengan usia >18 tahun, pasien CKD yang menjalani hemodialisis rutin (dua kali setiap minggu) selama $>3$ bulan, serta kriteria eksklusi berupa pasien yang mengalami kelemahan pasien dengan bedrest, pasien hemodialisis cito atau elektif. Sampel penelitian sejumlah 80 responden, pengambilan sampel menggunakan non probability sampling dengan teknik purposive sampling.

Penelitian ini menggunakan dua variabel yaitu variabel bebas dan variabel terikat. Interdialytic weight gain (IDWG) adalah variabel bebas sedangkan variabel terikat pada penelitian ini yaitu perubahan tekanan darah intradialisis. Instrumen pengumpulan data yang digunakan dalam penelitian ini berupa pengukuran IDWG yang dilakukan dengan cara mencatat berat badan pasien paska dialisis yang diperoleh dari rekam medis pasien pada hemodialisis sebelumnya, serta melakukan penimbangan berat badan pra dialisis setelah itu berat badan pradialisis dikurangi berat badan post dialisis kemudian hasilnya dibagi dengan berat badan pradialisis dan hasilnya dikalikan $100 \%$. Pengukuran tekanan darah pra dialisis dan intradialisis dengan menggunakan alat sphygnomanometer yang telah dikalibrasi. Pengukuran tekanan darah intradialisis dilakukan tiap satu jam selama proses dialisis (jam pertama setelah dialisis dimulai, jam kedua, jam ketiga, jam keempat, dan terakhir jam kelima setelah pasien mulai dialisis), kemudian dicari rata-rata tekanan darah yang selanjutnya menjadi tekanan darah intradialisis. Perubahan tekanan darah intradialisis menggunakan nilai MAP dimana dicari selisih nilai MAP pradialisis dengan MAP intradialisis.

Penelitian ini menggunakan dua analisis, yaitu analisis univariat dan analisis bivariat. Analisa univariat digunakan untuk menggambarkan distribusi frekuensi karakteristik responden (jenis kelamin dan umur). Pada penelitian ini analisis bivariat dapat diketahui ada hubungan yang signifikan antara interdialytic weight gain dengan perubahan tekanan darah intradialisis pada pasien CKD di Ruang Hemodialisis RSUP Sanglah Denpasar dengan $p$ value 0,001. Berdasarkan penelitian nilai $\mathrm{r}=0,589$. 


\section{HASIL DAN PEMBAHASAN}

\section{A. Hasil Penelitian}

1. Karakteristik Responden

Tabel 1. Distribusi Frekuensi Responden berdasarkan Umur di Ruang Hemodialisis RSUP Sanglah Denpasar (n=80)

\begin{tabular}{lll}
\hline Umur & $\begin{array}{c}\text { Frekuensi } \\
\text { (n) }\end{array}$ & \multicolumn{1}{c}{$\begin{array}{c}\text { Persentase } \\
\text { (\%) }\end{array}$} \\
\hline 26-35 tahun & 10 & 12,5 \\
36-45 tahun & 9 & 11,2 \\
$46-55$ tahun & 27 & 33,8 \\
$56-65$ tahun & 20 & 25,0 \\
>65 tahun & 14 & 17,5 \\
\hline Total & $\mathbf{8 0}$ & $\mathbf{1 0 0 , 0}$ \\
\hline
\end{tabular}

Berdasarkan tabel 1 dapat diketahui dari 80 responden sebagian besar responden berada pada rentang umur 46-55 tahun yaitu sebanyak 27 orang atau 33,8\%.

Tabel 2. Distribusi Frekuensi Responden berdasarkan Jenis Kelamin di Ruang Hemodialisis RSUP Sanglah Denpasar ( $\mathrm{n}=80)$

\begin{tabular}{ccc}
\hline Jenis Kelamin & Frekuensi (n) & Persentase (\%) \\
\hline Laki-Laki & 51 & 63,8 \\
Perempuan & 29 & 36,2 \\
\hline Total & $\mathbf{8 0}$ & $\mathbf{1 0 0 , 0}$ \\
\hline
\end{tabular}

Berdasarkan tabel 2 dapat diketahui dari 80 responden sebagian besar responden dengan jenis kelamin laki-laki yaitu sebanyak 51 orang atau $63,8 \%$.

2. Interdialytic Weight Gain pada Pasien CKD di Ruang Hemodialisis RSUP Sanglah Denpasar

Tabel 3. Distribusi Frekuensi Interdialytic Weight Gain pada Pasien CKD di Ruang Hemodialisis RSUP Sanglah Denpasar ( $\mathrm{n}=80)$

\begin{tabular}{ccc}
\hline Interdialytic Weight Gain & Frekuensi (n) & Persentase (\%) \\
\hline Ringan & 59 & 73,8 \\
Sedang & 21 & 26,2 \\
Berat & 0 & 0,0 \\
\hline Total & $\mathbf{8 0}$ & $\mathbf{1 0 0 , 0}$ \\
\hline
\end{tabular}

Berdasarkan tabel 3 dapat diketahui dari 80 responden sebagian besar interdialytic weight gain pada pasien CKD dalam kategori ringan yaitu sebanyak 59 orang $(73,8 \%)$. 
Jurnal IImu Keperawatan Medikal Bedah 3 (1), Mei 2020, 1-76

ISSN 2338-2058 (print), ISSN 2621-2986 (online)

3. Perubahan Tekanan Darah Intradialisis pada Pasien CKD di Ruang Hemodialisis RSUP Sanglah Denpasar

Tabel 4. Distribusi Frekuensi Perubahan Tekanan Darah Intradialisis pada Pasien CKD di Ruang Hemodialisis RSUP Sanglah Denpasar ( $\mathrm{n}=80)$

\begin{tabular}{ccc}
\hline $\begin{array}{c}\text { Perubahan Tekanan Darah } \\
\text { Intradialisis }\end{array}$ & Frekuensi (n) & Persentase (\%) \\
\hline Normal & 52 & 65,0 \\
Hipertensi & 4 & 5,0 \\
Hipotensi & 24 & 30,0 \\
\hline Total & $\mathbf{8 0}$ & $\mathbf{1 0 0 , 0}$ \\
\hline
\end{tabular}

Berdasarkan tabel 4 dapat diketahui dari 80 responden sebagian besar tekanan darah pada pasien CKD dalam kategori normal yaitu sebanyak 52 orang $(65,0 \%)$.

4. Distribusi Frekuensi Perubahan Tekanan Darah Intradialisis pada Pasien CKD di Ruang Hemodialisis RSUP Sanglah Denpasar

Tabel 5. Distribusi Frekuensi Perubahan Tekanan Darah Intradialisis pada Pasien CKD di Ruang Hemodialisis RSUP Sanglah Denpasar $(n=80)$

\begin{tabular}{|c|c|c|c|c|c|c|c|c|c|c|}
\hline \multirow{3}{*}{$\begin{array}{l}\text { Interdialytic } \\
\text { Weight Gain }\end{array}$} & \multicolumn{6}{|c|}{ Perubahan Tekanan Darah } & \multicolumn{2}{|c|}{ Total } & $P$ value & $r$ \\
\hline & \multicolumn{2}{|c|}{ Normal } & \multicolumn{2}{|c|}{ Hipertensi } & \multicolumn{2}{|c|}{ Hipotensi } & \multirow[t]{2}{*}{$\mathrm{n}$} & \multirow[t]{2}{*}{$\%$} & \multirow{6}{*}{0,001} & \multirow{6}{*}{0,598} \\
\hline & $\mathbf{N}$ & $\%$ & $\mathrm{~N}$ & $\%$ & $\mathrm{~N}$ & $\%$ & & & & \\
\hline Ringan & 49 & 61,2 & 0 & 0,0 & 10 & 12,5 & 59 & 73,8 & & \\
\hline Sedang & 3 & 38 & 4 & 5,0 & 14 & 17,5 & 21 & 26,6 & & \\
\hline Berat & 0 & 00 & 0 & 0,0 & 0 & 0,0 & 0 & 0,0 & & \\
\hline Total & 52 & 65,0 & 4 & 5,0 & 24 & 30,0 & 80 & 100,0 & & \\
\hline
\end{tabular}

Berdasarkan data pada tabel 5 menunjukkan bahwa sebagian besar pasien CKD yang memiliki interdialytic weight gain ringan sebanyak 49 orang $(61,2 \%)$ tidak mengalami perubahan tekanan darah atau masih dalam keadaan normal, 10 orang (12,5\%) mengalami hipotensi dan tidak ada yang mengalami hipertensi. Hasil uji statistik dapat diketahui p value sebesar 0,001 yang artinya ada hubungan yang signifikan antara interdialytic weight gain dengan perubahan tekanan darah intradialisis pada pasien CKD di Ruang Hemodialisis RSUP Sanglah Denpasar. Kuat lemahnya hubungan variabel dilihat dari koefisien korelasi $(r=0,598)$ menunjukkan hubungan yang sedang antar kedua variabel dengan sifat hubungan adalah positif, artinya bahwa semakin kecil nilai interdialytic weight gain maka semakin baik nilai selisih MAP pada pasien CKD. 
Jurnal IImu Keperawatan Medikal Bedah 3 (1), Mei 2020, 1-76

ISSN 2338-2058 (print), ISSN 2621-2986 (online)

\section{B. Pembahasan}

1. Interdialytic weight gain pada pasien CKD di ruang Hemodialisis RSUP Sanglah Denpasar

Interdialytic weight gain pada pasien CKD dari 80 responden sebagian besar dalam kategori ringan yaitu sebanyak 59 orang $(73,8 \%)$. Hasil penelitian ini menunjukkan sebagian besar pasien CKD mengalami penambahan berat badan 2-<4\%. Menurut Neumann (2013) IDWG yang dapat ditoleransi oleh tubuh adalah tidak lebih dari 3\% dari berat kering.

Faktor kepatuhan pasien dalam menaati jumlah konsumsi cairan menentukan tercapainya berat badan kering yang optimal, disamping ada faktor lain yang kemungkinan dapat meningkatkan IDWG diantaranya adekuasi hemodialisis, lama tindakan hemodialisis, kecepatan aliran hemodialysis, dan cairan dialisat yang digunakan (Smeltzer \& Bare, 2002). Hasil penelitian ini sesuai dengan penelitian yang telah dilakukan Atmaja (2013) di Unit Hemodialisis RSUP Haji Adam Malik Medan dengan 71 responden yang didapatkan hasil bahwa sebagin besar responden dalam penelitian tersebut termasuk dalam kategori ringan dengan jumlah 46 orang dengan persentase $(64,8 \%)$.

Berbeda dengan penelitian Risyanto (2011), yang dilakukan di unit hemodialisis IP2K RSUP Fatmawati Jakarta dengan jumlah responden 76 didapatkan hasil bahwa sebagian besar responden ada dalam kategori rata-rata dengan jumlah 49 (64,\%). Menurut Linberg, (2010) usia mempunyai hubungan yang signifikan dengan terjadinya penambahan IDWG. Usia juga merupakan faktor yang kuat terhadap tingkat kepatuhan pasien, dimana pasien dengan umur yang muda mempunyai tingkat kepatuhan yang rendah dibandingkan umur yang lebih tua.

Faktor jenis kelamin mempunyai faktor yang sama untuk terjadi peningkatan IDWG. Namun, kecenderungan laki-laki lebih rentan terkena CKD sehingga harus menjalani hemodialisis karena faktor pekerjaan laki-lakinlebih berat daripada perempuan, yang terkadang membuat lakilaki menkonsumsi minuman suplemen yang berlebih (Istanti, 2014). Peneliti berpendapat hasil penelitian sebagian besar responden mengalami peningkatan IDWG yang ringan yaitu sebanyak 49 orang $(61,2 \%)$, disebabkan oleh kepatuhan pasien dalam melaksanakan diet, serta karena paien telah diberikan edukasi yang berkala pada pasien CKD regular. 
Jurnal IImu Keperawatan Medikal Bedah 3 (1), Mei 2020, 1-76

ISSN 2338-2058 (print), ISSN 2621-2986 (online)

2. Perubahan Tekanan Darah Intradialisis pada Pasien CKD di Ruang Hemodialisis RSUP Sanglah Denpasar

Perubahan tekanan darah intradialisis pada pasien CKD di ruang RSUP Sanglah Denpasar dari 80 responden sebagian besar dalam batas normal yaitu sebanyak 52 responden $(65,0 \%)$, hipotensi sebanyak 24 Hemodialisis responden (30,0\%) dan hipertensi sebanyak 4 responden $(5,0 \%)$. Hasil penelitian ini menunjukkan perubahan tekanan darah intradialisis dalam batas normal, artinya adalah tidak terjadi peningkatan lebih dari $15 \mathrm{mmHg}$ atau penurunan tekanan darah lebih dari $10 \mathrm{mmHg}$. Penelitian ini sejalan dengan penelitian Inrig et al (2009) yang menyatakan bahwa kejadian hipertensi intradialitik terjadi pada 5-15\% dan Inrig et al, juga menemukan bahwa sebagian besar responden dengan hipertensi intradialisis berusia $>60$ tahun.

Berdasarkan penelitian ini didapatkan sebagian besar responden mempunyai tekanan darah intradialisi dalam batas normal sebanyak 52 responden $(65,0 \%)$ karena sebagian besar usia 46-55 tahun. Jika dikaitkan dengan teori patofisiologi hipertensi intradialisis mengenai hilangnya obat anti hipertensi selama proses hemodialisis dan adanya proses endotel yang lazim pada usia lanjut ,maka usia lanjut lebih berpotensi mengalami hipertensi intradialitik. Penelitian ini juga sejalan dengan hasil penelitian Mustikasari \& Dewi (2017) menyatakan bahwa tidak ada pengaruh yang signifikan antara jenis kelamin dengan IDWG. Laki-laki maupun perempuan mempunyai resiko yang sama untuk terjadinya peningkatan IDWG.

Hasil penelitian ini berbeda dengan penelitian yang dilakukan oleh Armiyati (2015), tentang hipotensi dan hipertensi intradialisis pada pasein CKD saat menjalani hemodialisis di RS PKU Muhammadiyah Yogyakarta dimana penelitian dilakukan pada 79 responden sebesar 70\% responden mengalami hipertensi intradialisis, $26 \%$ mengalami hipotensi intradialisis.

3. Hubungan antara Interdialytic Weight Gain dengan Perubahan Tekanan Darah Intradialisis pada Pasien CKD di Ruang Hemodialisis RSUP Sanglah Denpasar

Hasil analisis menunjukkan ada hubungan yang signifikan antara interdialytic weight gain dengan perubahan tekanan darah intradialisis pada pasien CKD di ruang Hemodialisis RSUP Sanglah Denpasar dengan p value 0,001. Berdasarkan penelitian nilai $r=0,589$ yang artinya kekuatan hubungan korelasi yang sedang antar kedua variabel dan sifat hubungan yang positif 
Jurnal IImu Keperawatan Medikal Bedah 3 (1), Mei 2020, 1-76

ISSN 2338-2058 (print), ISSN 2621-2986 (online)

yaitu semakin kecil nilai interdialytic weight gain maka semakin baik atau normal nilai selisih MAP intradialisis pada pasien CKD.

Penelitian ini sejalan dengan penelitian yang dilakukan oleh Lolyta, Ismonah, dan Solechan (2011) dengan judul “Analisis Faktor yang Mempengaruhi Tekanan Darah Hemodialisis pada Klien Gagal Ginjal Kronis" suatu studi di RS Telogorejo Semarang dengan rancangan explanatory yang menyatakan bahwa Interdialytic Weight Gain (IDWG) memiliki pengaruh yang signifikan terhadap tekanan darah hemodialisis pada klien dengan CKD ( $\mathrm{p}$ value $<0,05$ ). Selain itu, hasil penelitian tersebut juga menunjukkan untuk riwayat keluarga, diet, dan interdialytic weight gain memiliki pengaruh yang signifikan dengan tekanan darah klien yang menjalani hemodialisis ( $\mathrm{p}<0,05)$. Penelitian Widiyanto, Hadi, Wibowo (2013), tentang korelasi perubahan berat badan interdialisis dengan perubahan tekanan darah pasien post hemodialisis, menunjukkan terdapat hubungan antara perubahan berat badan interdialisis dengan perubahan tekanan darah ( $\mathrm{p}$ value $=$ 0,050). Hasil penelitian ini berbeda dengan hasil penelitian Liani (2016), tentang hubungan penambahan berat badan interdialisis dengan hipertensi intradialisis pada pasien penyakit ginjal kronik yang menjalani hemodialisis di RSD dr. Soebandi. Hasil penelitian tersebut menunjukkan dari 56 responden, angka kejadian hipertensi intradialisis pada CKD stadium V yang menjalani hemodialisis rutin sebesar 80,4\% dan insidensi atau angka kejadian penambahan berat badan interdialisis (interdialytic weight gain) sebesar $87,5 \%$ dengan nilai rata-rata penambahan berat badan interdialisis pasien sebesar $2,36 \mathrm{~kg}$. Hasil analisis lebih lanjut menunjukkan bahwa tidak terdapat hubungan yang bermakna antara penambahan berat badan interdialisis dengan hipertensi intradialisis pada pasien CKD yang menjalani hemodialisis di RSD dr. Soebandi Jember.

Berdasarkan hasil penelitian ini didapatkan sebagian besar responden mempunyai IDWG yang ringan dengan hasil $<4 \%$ dimana tekanan darahnya sebagian besar benilai normal hal tersebut berbeda dengan hasil penelitian Inrig et al. yang menemukan bahwa sebagian besar subyek dengan hipertensi intradialitik memiliki IDWG yang rendah. IDWG yang tinggi diidentikkan dengan kejadian hipotensi intradialitik yang berkaitan dengan tingginya laju ultrafiltrasi. Inrig et al. membuktikan kenaikan $1 \%$ persentase IDWG berhubungan dengan peningkatan 1,00 $\mathrm{mmHg}$ tekanan darah sistolik predialisis dan penurunan tekanan darah pascadialisis sehingga mendukung teori jika IDWG rendah lebih berpotensi terjadinya hipertensi intradialitik. Perbedaan tersebut disebabkan oleh perbedaan jumlah sampel dan karakteristik sampel. 
Jurnal IImu Keperawatan Medikal Bedah 3 (1), Mei 2020, 1-76

ISSN 2338-2058 (print), ISSN 2621-2986 (online)

Penyakit ginjal kronik atau CKD merupakan penyakit yang dapat dialami oleh semua orang sesuai etiologinya. Rentang usia pasien CKD yang menjalani hemodialisis di RSUP Sanglah Denpasar adalah 10 tahun sampai >65 tahun. Berdasarkan karakteristik usia, sebagian besar pasien yang menjalani hemodialisis adalah 45-55 tahun. Fungsi renal akan berubah dengan pertambahan usia. Sesudah usia 40 tahun terjadi penurunan laju filtrasi glomerulus secara progresif hingga usia 70 tahun (Smeltzer \& Bare, 2008). Selain itu, usia juga dapat mempengaruhi tekanan darah karena semakin menua usia seseorang, maka elastisitas arteri mengalami penurunan dan arteri lebih kaku dan kurang mampu merespon tekanan darah sehingga menyebabkan peningkatan tekanan darah (Kozier, 2010).

Selain usia, jenis kelamin juga merupakan faktor lain yang dapat mempengaruhi penambahan berat badan interdialitik dan tekanan darah. Sebagian besar pasien yang menjalani hemodialisis di RSUP Sanglah adalah laki-laki. Menurut penelitian Worden (2007), air total tubuh laki-laki membentuk $60 \%$ dari berat badannya, sedangkan air total tubuh perempuan membentuk $50 \%$ dari berat badannya. Air total tubuh akan memberikan penambahan berat badan yang meningkat lebih cepat sehingga terkait hal tersebut, maka penambahan berat badan interdialitik pada laki-laki lebih tinggi daripada perempuan. Selain itu jenis kelamin juga tidak hanya mempengaruhi penambahan berat badan interdialitik, tetapi juga dapat mempengaruhi tekanan darah. Menurut penelitian Prasetyaningrum (2014), bahwa laki-laki atau perempuan sama-sama memiliki kemungkinan beresiko terkena hipertensi. Berdasarkan penelitian di atas peneliti dapat menarik kesimpulan, selain jenis kelamin dan usia ada banyak faktor yang mempengaruhi IDWG dan perubahan tekanan darah intradialisis. Kepatuhan pasien adalah faktor yang paling penting, sehingga perlu ditingkatkan lagi pemberian edukasi secara berkala pada pasien HD regular.

\section{KESIMPULAN}

Berdasarkan hasil penelitian dan pembahasan di atas dari 80 responden maka dapat disimpulkan interdialytic weight gain pada pasien CKD sebagian besar dalam kategori ringan yaitu sebanyak 59 orang $(73,8 \%)$. Perubahan tekanan darah intradialisis pada pasien CKD di ruang Hemodialisis RSUP Sanglah Denpasar sebagian besar dalam batas normal yaitu sebanyak 52 orang $(65,0 \%)$. Ada hubungan yang signifikan antara interdialytic weight gain dengan perubahan tekanan darah intradialisis pada pasien CKD di ruang Hemodialisis RSUP Sanglah Denpasar 
dengan nilai $\mathrm{p}=0,001$ dan $\mathrm{r}=0,589$ kekuatan hubungan korelasi yang sedang antara kedua variabel dan sifat hubungan yang positif.

Bagi pelayanan keperawatan diharapkan dalam memberikan pelayanan keperawatan agar selalu memberikan edukasi kesehatan mengenai diet dan pembatasan intake cairan agar pasien HD dapat mempertahankan tekanan darah yang baik selama hemodialisis. Bagi perkembangan ilmu pengetahuan meningkatkan pengetahuan dan keterampilan petugas unit dialisis dalam memberikan edukasi sehingga dapat meningkatkan kualitas pelayanan pada pasien yang menjalani HD reguler. Bagi peneliti yang akan datang hasil penelitian ini bisa digunakan sebagai bahan pertimbangan untuk mengembangkan penelitian selanjutnya dengan membedakan secara spesifik faktor yang mempengaruhi IDWG dan tekanan darah. Bagi pasien CKD diharapkan agar tetap mempertahankan dan meningkatkan kemampuan untuk melakukan diet dan restriksi cairan agar tidak terjadi peningkatan IDWG. Selain itu, diharapkan kepada petugas kesehatan agar meningkatkan pemberian pendidikan kesehatan kepada pasien CKD mengenai diet rendah garam, pembatasan intake cairan, dan peningkatan kepatuhan pasien dalam menjalani diet.

\section{DAFTAR PUSTAKA}

Armiyati, Y. (2015). Hipotensi dan hipertensi intradialisis pada pasien Chronic Kidney Disease (CKD) saat menjalani hemodialisis di RS PKU Muhammadiyah Yogyakarta. Jurnal Seminar Hasil-Hasil Penelitian-LPPM UNIMUS. ISBN: 978-602-18809-0-6.

Atmaja, S. (2013). Korelasi Interdialytic Weight Gain (IDWG) dengan kejadian hipotensi intradialitik pada pasien gagal ginjal stadium di Unit Hemodialisis Rumah Sakit Umum Haji Adam Malik Medan. Karya Tulis Ilmiah dipublikasikan dalam http://repository. usu.ac.id/bitstream/123456789/40070/7.

Black \& Hawks. (2009). Medical surgical nursing: clinical management for positive outcome. Ed 7. Philadelphia: W.B. Saunders Company.

Chazot, C \& Jean, G. (2010). Intradialytic hypertension: it is time to act. Nephron Clinical Practice. 115:182-188.

Dinas Kesehatan Provinsi Bali. (2016). Profil kesehatan Dinas Kesehatan Provinsi Bali. Denpasar: Dinas Kesehatan Provinsi Bali.

Indonesian Renal Registry. (2015). $8^{\text {th }}$ Report of Indonesian Renal Registry (IRR). Jakarta: PERNEFRI.

Infodatin. (2017). Pusat Data dan Informasi Kementrian Kesehatan RI. ISSN 2442-7659.

Inrig, J., K. (2009). Intradialytic hypertension: a less-recognize cardiovascular complication of hemodialysis. Am J Kidney Disease. 55:108-118. 
Jurnal IImu Keperawatan Medikal Bedah 3 (1), Mei 2020, 1-76

ISSN 2338-2058 (print), ISSN 2621-2986 (online)

Irma, M., \& Erika, D., N. (2017). Faktor-faktor yang mempengaruhi nilai interdialytic weight gain pasien hemodialisis di RSUD Panembahan Senopati Bantul. GASTER Vol. XV No. 1 Februari 2017.

Istanti, Y., P. (2016). Faktor-faktor yang berkontribusi terhadap IDWG pada pasien Gagal Ginjal Kronik (GGK) yang menjalani hemodialisis di Unit Hemodialisis RS PKU Muhammadiyah Yogyakarta. Jurnal Mutiara Medika. Vol. 11 No. 2: 118-130.

Istanti, Y., P. (2014). Hubungan antara masukan cairan dengan Interdialytic Weight Gain (IDWG) pada pasien chronic kidney disease di Unit Hemodialisis RS PKU Muhammadiyah Yogyakarta. Jurnal PROFESI. Volume 10/September 2013-Februari 2014.

Kamyar, K., Z. (2009). Interdialytic weight gain, mortality linked. Nephrology Nursing Journal diakses 10 Juli 2018 dari http://www.renalandurologynews.com/hemodialysis/ interdialyticweight-gain-mortality-linked/article/127528/.

Kozier. (2010). Buku ajar fundamental keperawatan: konsep, proses, \& praktik. Volume: 1. Edisi: 7. Jakarta: EGC.

Liani, A., N. (2016). Hubungan penambahan berat badan interdialisis dengan hipertensi intradialisis pada pasien penyakit ginjal kronik yang menjalani hemodialisis di RSD dr. Soebandi. Skripsi. Program Studi Pendidikan Dokter Fakultas Kedokteran Universitas Jember.

Linberg, M. (2010). Excessive fluid overload among hemodialysis patients: prevalence, individual characteristic and self regulation of fluid intake. Disertasi. Faculty of Medicine.

Locatelli, F., Cavalli, A., \& Tucci, B. (2010). The growing problem of intradialytic hypertension. Nat Rev Neprhrol.

Lolyta, R., Ismonah, \& Solechan. (2011). Analisis faktor yang mempengaruhi tekanan darah hemodialisis pada klien gagal ginjal kronik. 17 April 2013.

Neuman, C. (2013). Body weight telemetry is useful to reduce interdialytic weight gain in patients with end-stage renal failure on hemodialysis. Journal of The American Telemedicine, Vol.1.

Nila, F., M. (2018). Upaya peningkatan promotif dan preventif bagi kesehatan ginjal di Indonesia. Jakarta.

Peixoto, M. R. G., Monego, E. T., Jardim, P. C. B. V., Carvalho, M. M., Sousa, A. L. L., Olivera, J. S., \& Neto, O. B. (2001). Diet and medication in the treatment of hyperuricemia in hypertensive patients. Arq Bras Cardiol, 76 (6), 468-572.

Prasetyaningrum, Y. I. (2014). Hipertensi bukan untuk ditakuti. Jakarta : Fmedia.

Widiyanto, P., Hadi, H., \& Wibowo, T. (2014). Korelasi positif perubahan berat badan interdialisis dengan perubahan tekanan darah pasien post hemodialisis. http://dx.doi.org/10.21927/jnki.2014.2(1).1-8.

Rahardjo, P., E. Susalit, \& Suhardjono. (2009). Buku ajar ilmu penyakit dalam: hemodialisis. Jakarta: Interna Publishing.

Riskesdas. (2013). Hasil riset kesehatan dasar tahun 2013. Jakarta: Badan Penelitian dan Pengembangan Kesehatan Kementrian Kesehatan Republik Indonesia.

Riyanto, W. (2011). Hubungan antara penambahan berat badan di antara dua waktu hemodialisis (Interdialysis Weight Gain = IDWG) terhadap kualitas hidup pasien penyakit ginjal kronik yang menjalani terapi hemodialisis di Unit Hemodialisis IP2K RSUP FATMAWATI

Lestari \& Saraswati / Hubungan antara interdialytic weight gain dengan perubahan tekanan darah... 44 
Jurnal IImu Keperawatan Medikal Bedah 3 (1), Mei 2020, 1-76

ISSN 2338-2058 (print), ISSN 2621-2986 (online)

Jakarta. Tesis dipublikasikan dalam http://lontar.ui.ac.id/file?file=digital/20282718T\%20Welas\%20Riyanto.pdf.

RSUP Sanglah Denpasar. (2017). Laporan tahunan instalasi pelayanan dialisis. Denpasar: RSUP Sanglah.

Smeltzer, S.C., \& Bare, B.G. (2010). Buku ajar keperawatan medikal bedah. Edisi 8, Volume 1. Jakarta: Penerbit Buku Kedokteran EGC.

Smeltzer, S.C., \& Bare, B.G. (2002). Buku ajar keperawatan medikal bedah. Edisi 8, Volume 1. Jakarta: Penerbit Buku Kedokteran EGC.

Smeltzer, S.C., \& Bare, B.G. (2008). Buku ajar keperawatan medikal bedah. Edisi 8, Volume 1. Jakarta: Penerbit Buku Kedokteran EGC.

Suwitra, K. (2009). Buku ajar ilmu penyakit dalam: penyakit ginjal kronis. 1035-1040. Jakarta: Interna Publishing.

United States Renal Data System [USRDS]. (2009). National Institutes of Health [NIH] and National Institue of Diabetes and Digestive Kidney Disease [NIDDK].

Worden, V. (2007). Gender, age, and geographical location on of renal replacement therapy. diakses dari http://www.medscape.com/viewarticle/5601584. 